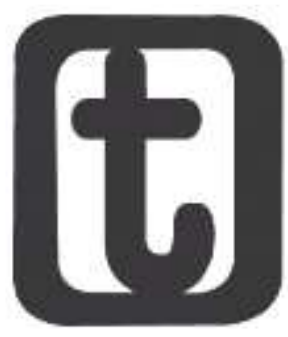

\title{
HEGEMONIA NEOLIBERAL NO BRASIL: IMPLICAÇÕES PARA POLÍTICA DE ASSISTÊNCIA SOCIAL
}

\author{
Gabriele Ponciano da Silva* \\ https://orcid.org/0000-0002-5192-6730
}

Neoliberal hegemony in Brazil: implications for social assistance policy

\begin{abstract}
RESUMO
O presente trabalho trata sobre o avanço do neoliberalismo no Brasil e as implicações para Política de Assistência Social, tendo em vista que o desenvolvimento desta política coincidiu com o avanço da hegemonia neoliberal e a instauração de uma agenda contrarreformista no país, a partir da década de 1990. Para tanto, versa sobre as construções e contradições constitutivas desse processo, considera e apresenta as tendências que vem transparecendo e conformando o caráter da Política de Assistência Social brasileira. A compreensão do objeto de estudo foi realizada através de movimento abstração da realidade concreta, a partir da apreensão das mediações necessárias para uma análise da totalidade. As aproximações apontaram o contexto adverso em que a Política de Assistência Social vem sendo gestada e desenvolvida.
\end{abstract}

\section{PALAVRAS-CHAVE}

Neoliberalismo. Contrarreforma. Política de Assistência Social.

\begin{abstract}
The present work deals with the advance of neoliberalism in Brazil and the implications for Social Assistance Policy, considering that the development of this policy coincided with the advance of neoliberal hegemony and the establishment of a counter-reformist agenda in the country, from the decade of 1990. Therefore, it deals with the constructions and contradictions constituting this process, considers and presents the trends that have been showing and shaping the character of the Brazilian Social Assistance Policy. The comprehension of the object of study was accomplished through an abstraction movement from the concrete reality, from the apprehension of the necessary mediations for an analysis of the totality. The approximations pointed to the adverse context in which the Social Assistance Policy has been developed and developed.
\end{abstract}

KEYWORDS: Neoliberalism. Counter-reformation. Social Assistance Policy.

Submetido em: 9/2/2020.

Aceito em: 23/4/2020.

\footnotetext{
* Assistente Social. Doutoranda em Serviço Social pela Universidade Federal de Juiz de Fora. (UFJF, Juiz de Fora, Brasil). Rua José Lourenço Kelmer, $s / n$, Campus Universitário, Bairro São Pedro, Juiz de Fora (MG), CEP: 36036-900. E-mail: gabriele.ponciano@gmail.com.
}

DOI 10.22422/temporalis.2020v20n39p57-69

(cc) $\mathrm{BY}$ (c) A(s) Autora(s)/O(s) Autor(es). 2019 Acesso Aberto Esta obra está licenciada sob os termos da Licença Creative Commons Atribuição 4.0 Internacional (https://creativecommons.org/licenses/by/4.o/deed.pt_BR), que permite copiar e redistribuir o material em qualquer suporte ou formato, bem como adaptar, transformar e criar a partir deste material para qualquer fim, mesmo que comercial. O licenciante não pode revogar estes direitos desde que você respeite os termos da licença.

Temporalis, Brasília (DF), ano 20, n. 39, p. 57-69, jan./jun. 2020. | ISSN 2238-1856 


\section{temporalis}

\section{INTRODUÇÃO}

$\mathrm{O}$

contexto de implementação da Política de Assistência Social no Brasil, a partir da década de 1990 se apresenta com o aprofundamento da crise estrutural e global do capital sob a instauração de uma onda longa de recessão econômica (MANDEL, 1982. Grifos nossos) que desde a década de 1970, sobretudo, na década 1980 requisitou estratégias de recomposição e ampliação do capital. No Brasil, tais estratégias significaram um redirecionamento das conquistas aludidas na Constituição Federal de 1988 com um destaque ao Sistema de Seguridade Social que sofreu impactos profundos a partir das contrarreformas de cariz neoliberal que passou a orientar a gestão pública brasileira.

No primeiro governo do Partido dos Trabalhadores (PT) foi possível a intervenção de forças democráticas na defesa da proposta da Política de Assistência Social prevista na CF de 1988 e na Lei Orgânica de Assistência Social (1993) o que culminou na extinção do Programa Comunidade Solidária e na rearticulação do Conselho Nacional de Assistência Social, o que por sua vez possibilitou a aprovação da Política Nacional de Assistência Social (PNAS), em 2004, a qual veio no sentido de descrever e orientar a organização da Assistência Social em território nacional. Posteriormente, tem a aprovação do Sistema Único de Assistência Social, sistematizado nas Normas Operacionais Básicas (NOB-SUAS; NOB-RH) as quais abarcam os condicionantes no que se refere, ao financiamento, a constituição da rede sócio assistencial, os recursos humanos e infraestrutura e a participação e controle social, para implementação da Política de Assistência Social em âmbito nacional.

Compreendemos o significado de tais avanços no campo institucional e legal da organização da Política de Assistência Social em âmbito nacional, haja vista o seu histórico na formação econômico e social brasileira, atrelada a ideia do favor e benesse. Contudo, dada a permanência e aprofundamento da lógica neoliberal ao longo dos governos do PT expresso por um pacto social, como designou lasi (2017), ou projeto de concertação social, como considerou Demier (2017), os avanços preconizados no âmbito da Política de Assistência Social foram gestados e implementados ancorados nos princípios neoliberais que foram decisivamente funcionais a democracia de cooptação que vigorou no país ao longo dos governos do PT.

Tal tendência é perceptível ao reportarmos para o orçamento da política de assistência social, em que o mesmo demonstra que mais de $90 \%$ dos recursos dessa política historicamente são destinados aos programas de transferência de renda, tal dado revela a contradição no processo de implementação do SUAS, considerando a centralidade da destinação dos recursos aos programas de transferência de renda e uma fragilidade na garantia de recursos voltados para estruturação dos serviços que constituem tal política. Posto isso, o referido trabalho, através de um estudo teórico, objetiva apresentar as construções e contradições constitutivas do processo de consolidação da Política de Assistência Social, considera e apresenta as tendências que vem transparecendo e conformando o caráter de tal política.

\section{POLÍTICA DE ASSISTÊNCIA SOCIAL NA DÉCADA 1990: TENDÊNCIAS E DESDOBRAMENTOS}

A captura da proposta de Seguridade Social pelo ideário neoliberal desencadeada principalmente nos governos de Fernando Henrique Cardoso (1995-1998 e 1999-2002) 
provocou um aprofundamento das contradições históricas do país, já que era a primeira vez que o mesmo experimentava a possibilidade de organização de um Sistema de Proteção Social pautado em princípios universais e democráticos [...] portanto, diminuiu o que não existia e redefiniu o que foi construído, sendo assim, assistencialização, mercantilização, re-filantropização e focalização das políticas sociais formaram a tendência de tal proposição (MOTA, 2008). Assim,

[...] a conjuntura hegemônica do governo FHC apresentou, portanto, um modelo econômico e social (ajuste neoliberal que aposta numa política econômica ortodoxo-monetarista, supervalorizando a estabilização e o controle inflacionário e a redução do papel do Estado na área social) incompatível com a universalização e aprofundamento de direitos sociais (FIORI, 1995; SOARES, 2001 apud ANTINARELI et al., 2012, p. 16).

O Plano Diretor da Reforma do Estado ${ }^{1}$ proposto durante o governo de Fernando Henrique Cardoso, influenciado pela perspectiva neoliberal, expressa o redirecionamento das prioridades do Estado no que se refere às políticas econômicas e sociais no país, ou seja, o estabelecimento de uma agenda de reajustes no campo social e econômico a fim de atender aos interesses do capital, aludia no documento que ficou conhecido como Consenso de Washington ${ }^{2}$. Concordamos com Simionatto (1999) quando afirma que,

As principais diretrizes dos organismos internacionais recomendam que a Reforma do Estado seja orientada para o mercado, exigindo o abandono de instrumentos de controle político e a restrição na alocação de recursos públicos, principalmente na área social. As agências de cooperação internacional, especialmente o Banco Mundial, têm articulado uma 'aliança tecnocrática transnacional', no sentido de racionalizar os investimentos nessa área, diminuindo o papel do Estado e fortalecendo as ações de natureza privada (SIMIONATTO, 1999, p. 1).

É sob essa contextura, de reajustes no campo social e econômico, que se processa a proposta do Sistema de Seguridade Social no Brasil, muito aquém do que havia sido nas

\footnotetext{
${ }^{1}$ Ao abordar o processo que configurou a sistematização do referido documento bem como suas tendências, Duriguetto (2007, p. 176) explicita: "A proposta desta reforma - denominada de reforma administrativa surgiu no âmbito do Ministério da Administração Federal e Reforma do Estado (MARE) sob a gestão do ministro Bresser Pereira. Essa reforma começou a ser implementada por meio de um 'Plano Diretor' redigido no primeiro semestre de 1995, em que se destaca a defesa do chamado modelo gerencial. Tal modelo, em linhas gerais, objetiva dotar o aparelho estatal de mais 'governança' e de mecanismos político-institucionais mais eficientes para executar suas funções. O conceito de 'governança' é aqui utilizado para referir-se à incapacidade financeira e administrativa do Estado brasileiro de concretizar suas decisões. Essa dupla incapacidade é, segundo Bresser, extremamente acentuada pelos preceitos contidos na Carta de 1988. Refere-se às conquistas sociais contidas na Constituição como 'retrocesso burocrático' (BRESSER PEREIRA, 1998, p. 163 apud DURIGUETTO, 2007, p. 176), podendo, tais conquistas, se implementadas, perpetuar e agravar nossa histórica herança de uma relação Estado/sociedade marcada pelo clientelismo, patrimonialismo e pela burocracia. Dotar o Estado de amplas responsabilidades sociais também implica no agravamento da crise fiscal do Estado que, para Bresser, é a principal responsável pela crise da década de $1980 "$.

${ }^{2}$ Foi elaborado em 1989 tendo como protagonistas nesse processo o Fundo Monetário Internacional (FMI) e Banco Mundial, nesse documento constam medidas que preveem mudanças nas funções do Estado, evidenciando, sobretudo o fortalecimento de políticas macroeconômicas.
} 


\section{temporolis}

experiências europeias ${ }^{3}$, e que já nesse estágio de crise estrutural do capital experimentava dos desmontes expressos pela nova estratégia de reordenamento econômico influenciado pelas perspectivas neoliberais. Assim, a experiência brasileira no campo da formulação de um Sistema de Proteção Social efetivo, de caráter universal, público, democrático, participativo e de qualidade, tem se dado em um campo extremamente adverso e de apelo a não garantia do mesmo, conformando na concretude um sistema de proteção social distante do que fora previsto pela Constituição Federal de 1988. Nessa direção Mota (2010, p. 138) afirma:

[...] é importante destacar que o momento político que marcou a definição na Seguridade Social na Constituição de 1988 deve ser reconhecido como expressão de resistência e autonomia dos setores progressistas da sociedade brasileira, já que o cenário internacional era adverso a qualquer iniciativa de intervenção social do Estado em face das críticas neoliberais ao WelfareState nos países desenvolvidos [...] essas disjunção entre tendências internacionais e a particularidade local apontava, ainda que 'tardiamente', para a expansão e consolidação de um sistema de seguridade social, nele incluindo a Assistência Social, como uma das políticas que, ao lado da Previdência e da Saúde, integravam o sistema. Essa expectativa, entretanto, a partir dos anos 1990, começa a ser ameaçada por uma agenda de prescrições neoliberais e de reformas voltadas para a descaracterização dos recém-instituídos direitos sociais (MOTA, 2010, p. 138).

No âmbito da Assistência Social, o governo FHC pautou-se em duas frentes: o apelo à solidariedade e os programas de transferência de renda (ANTINARELI et al., 2012). No que se refere a solidariedade destaca-se a propagação e instauração do Programa Comunidade Solidária4 (1995) que paralelo a LOAS (1993) imputa uma proposta de organização da assistência social no país, no entanto esse programa se apresentou no sentido de deturpar a proposta (ainda que limitada5) da LOAS, apelando para um movimento contrário de desresponsabilização do Estado no trato da Política de Assistência Social. Ou seja, o programa Comunidade Solidária obstaculizou o desenvolvimento da proposta aludida pela CF/1988 e LOAS (1993), retardando o processo da organização efetiva da Política de Assistência Social por quase uma década.

Outro reflexo desse processo de redirecionamento das propostas aludidas pela Constituição Federal de 1988 e a LOAS (1993) foi [...] a implantação de programas de transferência de renda com condicionalidades (como Bolsa-Escola, Bolsa Alimentação, Vale Gás, Programa de Erradicação do Trabalho Infantil etc.), através de critérios restritos de elegibilidade e de distribuição de benefícios ínfimos (ANTINARELI et al., p. 17), o que implicou a estruturação do Sistema de Proteção Social, baseado nesses aspectos de apelo

\footnotetext{
3 Essas experiências foram possíveis sob a estruturação do Estado de Bem Estar Social durante as décadas de 1940 - 1970 na Europa instaurou uma política econômica pautado pensamento keynesiano que prima pela regulação estatal nos setores econômicos e sociais amparado pela política de pleno emprego.

${ }^{4}$ No Brasil, o governo FHC, em detrimento do que reza a Lei Orgânica de Assistência Social (LOAS), tem investido no programa Comunidade Solidária, dirigido pela primeira-dama, desviando recursos de atividades de responsabilidade estatal para o terceiro setor. Desvio claramente inspirado nos ditames do Consenso de Washington (MONTAÑO, 2002, p. 216).

${ }^{5}$ A LOAS trás inúmeros avanços no que se refere a organização da assistência social no Brasil, sobretudo, na gestão participativa primando pela participação da população na elaboração e implementação da política, no entanto não podemos perder de vista o teor seletista e distributivo presente na mesma que reafirma o caráter focalista e minimalista da assistência social no país.
} 
a solidariedade, focalização e seletividade, e, sobretudo, na desarticulação das políticas que compõem o Sistema de Seguridade Social.

Sobre essa questão, concordamos com Mota ao afirmar que:

[...] as políticas que integram a seguridade social brasileira longe de formarem um amplo e articulado mecanismo de proteção, adquiriram a perversa posição de conformarem uma unidade contraditória: enquanto avançam a mercantilização e privatização das políticas de saúde e previdência, restringindo o acesso e os benefícios que lhes são próprios, a assistência social se amplia na condição de política não contributiva, transformando-se num novo fetiche de enfrentamento à desigualdade social, na medida em que se transforma no principal mecanismo de proteção social no Brasil (MOTA, 2010, p. 134).

A centralidade da Política de Assistência Social no desenvolvimento do Sistema de Seguridade Social está associada às repercussões da crise estrutural do capital expressas pelo aumento do desemprego e da pobreza. Nesse ínterim, o direcionamento da Política de Assistência Social nos moldes previstos pela lógica neoliberal, a qual tem capitaneado o Sistema de Seguridade Social, está voltado para uma perspectiva de gestão da pobreza e apaziguamento das lutas de classes. Ou seja, a organização da Política de Assistência Social pautada nos programas de renda mínima demonstra que sua implementação se deu [...] sob uma nítida concepção liberal de focalização e pobreza absoluta, o que contribuiu para a redução de gastos sociais (ANTINARELI et al., 2012, p. 17).

Nesse quadro, as estratégias de focalização - via programas de combate à pobreza - e descentralização/apelo à solidariedade e voluntariado contribuem, como sinalizam Laurell (1995) e Soares (2000), para a manutenção de mecanismos clientelistas na área social. Esse aspecto parece bem razoável em se tratando de um governo fundado num pacto conservador, que precisa articular politicamente apoio para a direção estratégica maior: a transnacionalização radical da economia (FIORI, 2001 apud ANTINARELI et al., 2012, p. 17).

Como supracitado todo esse processo está inserido em um movimento mais amplo que diz respeito ao reordenamento da economia pautada nos princípios neoliberais que já vinham sendo perpetuados na Europa, provocando desmonte aos direitos conquistados durante o Estado de bem-estar social. Todavia, no Brasil os direitos recém-conquistados na Constituição Federal de 1988 foram descaracterizados e redirecionados para a lógica de mercado antes mesmo de sua consolidação. Tal como afirma Simionatto (1999),

Os programas de ajuste estrutural, necessários ao fortalecimento das políticas macroecômicas, são compostos por três elementos básicos: redução dos gastos públicos, realocação de recursos necessários ao aumento de superávits na balança comercial e reformas visando aumentar a eficiência do sistema econômico. Tais orientações, que se colocam como exigências para a inserção das economias nacionais no processo de globalização capitalista, incidem diretamente sobre as políticas públicas de corte social, na medida em que impõem cortes nos orçamentos e redução do gasto público. O Estado é entendido aqui não mais como o provedor de serviços públicos, mas como promotor e regulador, devendo estabelecer suas funções de acordo com sua capacidade (SIMIONATTO, 1999, p. 2). 


\section{temporolis}

Ao longo do governo FHC tem-se o acirramento das prerrogativas neoliberais no país, fundamentados na tríade maldita ${ }^{6}$ (superávit primário; redução dos gastos e câmbio flutuante) o que intensificou os seus impactos no cenário brasileiro. Esses três elementos, que se colocam como exigências para a inserção das economias nacionais no processo de globalização capitalista em tempos de hegemonia das finanças, incidem diretamente sobre as políticas públicas de corte social, na medida em que impõem cortes nos orçamentos e redução do gasto público. "O Estado é entendido aqui não mais como o provedor de serviços públicos, mas como promotor e regulador, devendo estabelecer suas funções de acordo com sua capacidade" (SIMIONATTO, 1999, p. 2).

\section{CONSOLIDAÇÃO DA CIDADANIA DE CONSUMO E A POLÍTICA DE ASSISTÊNCIA SOCIAL BRASILEIRA}

Assim "[...] devido o quadro político instaurado, a sociedade brasileira elege Lula para Presidência da República em 2002, e o reelege em 2006" (ANTINARELI et al., 2012, p. 18). No primeiro governo do Partido dos Trabalhadores (PT) foi possível a intervenção de forças democráticas na defesa da proposta da Política de Assistência Social prevista na CF de 1988 e na Lei Orgânica de Assistência Social (1993) o que culminou na extinção do Programa Comunidade Solidária e na rearticulação do Conselho Nacional de Assistência Social, o que por sua vez possibilitou a aprovação da Política Nacional de Assistência Social (PNAS), em 2004, a qual veio no sentido de descrever e orientar a organização da Assistência Social em território nacional. Posteriormente, tem a aprovação do Sistema Único de Assistência Social, sistematizado nas Normas Operacionais Básicas (NOB-SUAS; NOB-RH) as quais abarcam os condicionantes no que se refere, ao financiamento, a constituição da rede sócio assistencial, os recursos humanos e infraestrutura e a participação e controle social, para implementação da Política de Assistência Social em âmbito nacional. É notório o significado de tais avanços no campo institucional e legal da organização da Política de Assistência Social em âmbito nacional, haja vista o seu histórico na formação econômico e social brasileira, atrelada a ideia do favor e benesse.

Todavia, o que se observa no curso dos governos do PT é uma manutenção das prerrogativas neoliberais que "[...] através das metas de inflação, do ajuste fiscal permanente e do câmbio flutuante, o Brasil passou o governo Lula" (ANTINARELI et al., 2012, p. 18), bem como durante o governo de Dilma Rousseff. Os governos do PT foram sustentados por um pacto social a partir de lasi (2017) ou projeto de concertação social de acordo com Demier (2017). Tal processo foi possível por meio de uma articulação entre a pequena burguesia política, representada pelo PT, e setores das camadas dominantes da burguesia monopolista (industrial, agrária, comercial e financeira), que mediante os termos da democracia de cooptação, buscou a adesão dos segmentos da classe trabalhadora, oferecendo muito pouco em termos de direitos e acesso a bens e serviços. Em suma,

[...] Nos termos idealizados do pacto e da democracia de cooptação, todos sairiam ganhando: os trabalhadores, pelo aumento da oferta de emprego (ainda que achatando os salários no topo da pirâmide de assalariados e precarizando direitos e vínculos trabalhistas) e pelo acesso ao consumo via facilitação de crédito; para aqueles abaixo da linha da miséria absoluta (menos de um dólar ao dia), com

\footnotetext{
${ }^{6}$ Nos dizeres do Professor José Fernando Siqueira da Silva, professor da Unesp/Franca, na palestra organizada pelo CRESS- $6^{\circ}$ região no dia do Assistente Social Em 16/05/2016.
}

Temporalis, Brasília (DF), ano 20, n. 39, p. 57-69, jan./jun. 2020. | ISSN 2238-1856 
políticas compensatórias como a bolsa família; para os grandes empresários do capital monopolista, além das condições macroeconômicas e o saneamento do Estado, subsídios diretos e 'previsibilidade' para fazer seus investimentos e garantir taxas de lucro (IASI, 2017, p. 322-323).

lasi (2017, p. 323) chama a atenção que "o meio para viabilizar o pacto seria o desenvolvimento de um mercado de consumo de massas, que exigiria facilidades para o capital em todos os seus setores: industrial, exportador e importador, agrário etc." Dialoga com essa tendência a centralidade do orçamento da Política Assistência Social, voltada para os programas de transferência de renda e não para a estruturação dos serviços que constituem o Sistema Único de Assistência Social. Em uma análise dos dados da Controladoria Geral da União (CGU), no ano de 2013, referente a utilização dos recursos alocados no orçamento da Política de Assistência Social , Schmidt e Silva (2015) fizeram a seguinte síntese:

Os dados indicam que grande parte dos recursos alocados na Política de Assistência Social refere-se aos programas de transferência de renda, como o Programa Bolsa Família e o Benefício de Prestação Continuada (BPC). Os dados da CGU informam o valor de $\mathrm{R} \$ 28,2$ bilhões relativos à Assistência Comunitária, onde está incluído o PBF. Segundo dados do Portal da Transparência, cerca de R\$ 24,8 bilhões foram repassados pelo Governo Federal, em 2013, para o PBF (BRASIL, 2014), ou seja, a maior parte do recurso da Assistência Comunitária destina-se ao PBF. Verificamos, assim, o direcionamento da Política de Assistência Social na atualidade, com o foco na implementação dos PTR, focalizados na pobreza extrema (SCHMIDT; SILVA, 2015, p. 7).

Essa constatação da centralidade dos recursos da Política de Assistência Social nos programas de transferência de renda, não é no sentido de questionar a necessidade destes, tendo em vista os efeitos nocivos do atual estágio de acumulação capitalista, marcado pelo desemprego estrutural, e o compromisso prioritário do Estado em garantir as condições para os interesses do capital financeiro. Contudo, não podemos perder de vista a funcionalidade dessa tendência, que reforça mais uma vez a seletividade e focalização no conteúdo da Política de Assistência Social, caracterizada pela prevalência de uma cidadania do consumo, a fim de corresponder à lógica do mercado de consumo de massas que persistiu nos governos do PT.

lasi (2017) ainda ao considerar o pacto que atravessou os governos do PT, destaca que a princípio "[...] os efeitos do pacto se fizeram sentir em níveis de crescimento econômico, de emprego e de consumo, que garantiram patamares razoáveis para a acumulação de capitais e o funcionamento da democracia de cooptação" (IASI, 2017, p. 323). Reside neste processo o crescimento da exportação de commodities em um cenário econômico internacional favorável que provocou uma estabilidade mínima ao país, mas significou o aprofundamento da dependência econômica do mesmo. Carcanholo (2010) sintetiza:

\footnotetext{
A melhora das contas externas só ocorreu por uma eventualidade conjuntural dos seguintes fatores: (i) alta no ciclo de liquidez internacional, o que reduz as taxas internacionais de juros, proporcionando um crescimento da economia mundial e uma redução no risco-país, que embasa o fluxo de capitais externos; (ii) forte crescimento da economia chinesa, que importa os produtos justamente que preponderam na pauta de exportações da economia brasileira; (iii) crescimento do preço das commodities, predominantes na estrutura exportadora do país (CARCANHOLO, 2020, p. 123).
} 


\section{temporolis}

É importante ponderar que a aplicabilidade do pacto culminou no apassivamento da classe trabalhadora a partir de um movimento duplo que pode ser constatado a partir da captura das lideranças de movimentos sociais e sindicais para ocupar as instâncias institucionais do governo e, concomitantemente, a abrangência de políticas sociais compensatórias e focalizadas a fim de administrar7, no campo do imediato, as necessidades e demandas dos segmentos subalternizados, é nesse processo que os programas de transferência de renda cumpriram uma função fundamental. Para tanto o pacto garantiu

[...] a inviabilização do Estado como indutor de um desenvolvimento, mesmo nos termos reformistas ou semirreformistas apontados pelo programa do PT. As políticas sociais têm que se manter nos limites das políticas compensatórias e focalizadas tal como defendidas pelo Banco Mundial; os serviços públicos não podem dar o salto necessário para enfrentar sua grave crise de sucateamento aprofundada por décadas de descaso. Mais uma vez, a solução beneficia a lógica do mercado: as parcerias público-privadas e a intensificação das privatizações (IASI, 2017, p. 324).

Ao considerar esse cenário, mais especificamente no quadro das eleições de 2006 em que Lula/PT foi eleito para seu segundo mandato, Oliveira (2010) explicitou:

[...] Talvez estejamos assistindo à construção de uma 'hegemonia às avessas' típica da era da globalização [...] A longa 'era da invenção' forneceu a direção moral da sociedade brasileira na resistência à ditadura e alçou a questão da pobreza e da desigualdade ao primeiro plano da política. Chegando ao poder, o PT e Lula criaram o Bolsa Família, que é uma espécie de derrota do apartheid. Mais ainda: ao elegermos Lula, parecia ter sido borrado para sempre o preconceito de classe e destruídas as barreiras da desigualdade. Ao elevar-se à condição de condottiere e de mito, como as recentes eleições parecem comprovar, Lula despolitiza a questão da pobreza e da desigualdade. Ele as transforma em problemas de administração, derrota o suposto representante das burguesias - 0 PSDB, o que é inteiramente falso - e funcionaliza a pobreza. Esta, assim, poderia ser trabalhada no capitalismo contemporâneo como uma questão administrativa (OLIVEIRA, 2010, p. 24-25).

A administração da pobreza $a^{8}$ ganhou notoriedade no desenvolvimento do pacto social dos governos do PT. Todavia, lasi (2017, p. 348) enfatiza que “o equilíbrio do governo de pacto social sempre foi difícil uma vez que supõe poder conciliar o que é inconciliável, isto é, os interesses das classes antagônicas. E pressupõe, também, uma estabilidade econômica e uma governabilidade negociada por meio de cargos no governo". Posto isto, a partir de 2008, com a mudança da conjuntura econômica externa, os anos que seguiram têm sido

\footnotetext{
7 "Destacam-se nesse processo a abrangência da expansão da cidadania e a inclusão social por meio de programas sociais, entre os quais a transferência de renda, o aumento do salário mínimo, programas sociais como o Bolsa Família, cotas de admissão em universidades e no serviço público, a expansão do acesso aos bens públicos, etc." (SAAD; MORAIS, 2018, p. 246).

${ }^{8}$ Durante os governos do PT, houve redistribuição da renda por meio do maior acesso a aposentadorias, programas de transferência de renda e crédito ao consumidor, além de maiores ganhos no mercado de trabalho. No entanto, ao contrário do ocorrido com a social-democracia europeia do pós-guerra, o consumo de massa coexistiu com a preservação da desigualdade de riqueza e com um padrão de empregos em franca deterioração. Ou seja, à medida que os rendimentos dos mais pobres aumentavam, a pobreza diminuía e os salários tornavam-se menos desiguais; ao mesmo tempo, os ricos preservavam seus rendimentos, e empregos continuavam precários e mal remunerados (SAAD; MORAIS, 2018, p. 164).
} 
de aprofundamento da crise econômica do país, aprofundamento que provocou fissuras ao pacto estabelecido durante a ascensão do PT ao poder. Se nos dois mandatos de Lula (2003-2006; 2007-2010) tais fissuras foram sendo contidas, com os impactos da crise cada vez mais aparentes, o governo de Dilma (2011-2014; 2015-2016) teve dificuldades de se legitimar e reafirmar o pacto.

[...] a partir da segunda metade do primeiro mandato de Dilma Rousseff, a situação infletiu visivelmente, com o desemprego aumentando e a inflação corroendo fortemente o poder de compra dos trabalhadores (que nunca foi alto, mas era significativo para os padrões nacionais das últimas décadas, sobretudo em função dos créditos consignados) e dos setores médios, estrangulados - assim como os assalariados - pela estrutura tributária do país, profundamente regressiva [...] O descontentamento social cresceu celeremente. As Jornadas de Junho de 2013 foram, de certa forma, uma expressão dessa nova situação. $O$ alto custo de vida, o caos nos serviços públicos, e nos transportes em particular, tornou a vida quase insuportável para a maior parte da população, que iniciou vertiginosamente uma ruptura como o petismo no poder. Diante disso, até mesmo a capacidade do PT de domesticar os movimentos sociais e aplicar os ajustes tornou-se menor, diminuindo, por conseguinte, a sua serventia política ao capital (DEMIER, 2019, p. 40).

Ainda nessa direção, lasi (2017, p. 427) pondera que a mudança do cenário econômico mundial e o consequente agravamento da crise na periferia do sistema fez com que as bases da democracia de cooptação e do governo de pacto social deteriorassem rapidamente. De modo que, as manifestações de $2013^{9}$ tocaram em uma das principais bases do pacto, isto é, a eficiência do apassivamento. Em suma, ao diminuir a capacidade de manter o apassivamento dos movimentos sociais e, ao mesmo tempo, aplicar ajustes, o governo do pacto social, sobretudo, a democracia de cooptação sustentada por este vai perdendo a utilidade para a hegemonia burguesa.

É importante salientar que o cenário político brasileiro pós jornadas de junho foi marcado por uma guinada conservadora, que acabou por ganhar ressonância - ainda no bojo do movimento - com a propagação do apoliticismo e com a centralidade da pauta anticorrupção como justificativa para todos os males no âmbito social e econômico do país. Contudo, é em torno das eleições presidenciais de 2014, sobretudo, após o resultado desta, que a guinada conservadora acelera o processo corrosivo da democracia de cooptação e do pacto que a sustentava.

O pleito presidencial de 2014 evidenciou o recuo das frações dominantes na sustentação do pacto e foi marcado pelos acirramentos provocados, em certa medida, pela guinada conservadora. Mesmo nesse cenário, Dilma Rousseff/PT conseguiu se reeleger com uma pequena margem de votos à frente de seu adversário Aécio Neves/PSDB. Não obstante, no segundo mandato de Dilma, o aprofundamento da crise econômica conferiu o esgarçamento total do pacto social sustentado ao longo dos governos petista. De modo

\footnotetext{
9 Em junho de 2013 ocorreram grandes mobilizações de massa nas ruas de todas as capitais do país. Inicialmente impulsionadas pela juventude organizada pelo Movimento Passe Livre-MPL contra o aumento da tarifa dos transportes, na sequência se ampliaram com a participação de diversos segmentos dos trabalhadores e com um amplo leque de protestos como o alto custo de vida e a ausência e/ou precarização de serviços de educação, saúde e habitação. Em 2014, os gastos com a Copa do Mundo em detrimento dos gastos com a educação, saúde, transporte, habitação, reforma agrária geraram também grandes mobilizações, que foram fortemente reprimidas (DEMIER; DURIGUETTO, 2017, p. 15-6).
} 
que a crise econômica instigou e fortaleceu uma ação conjunta das frações da burguesia para a recuperação do crescimento econômico. Tal recuperação seria subsidiada pelas medidas contrarreformistas e no constante ajuste fiscal. É importante ponderar que, "[...] para a burguesia, esta recuperação não seria possível de ser levada a cabo pelo PT no ritmo exigido pelo cenário de recessão econômica” (DEMIER, 2019, p. 28). Em suma, “[...] este é o foco que cimentou a unidade de ação das diferentes frações da burguesia para a deposição da presidente Dilma, no dia 31 de agosto de 2016" (DEMIER; DURIGUETTO, 2017, p. 13, grifos dos autores).

De acordo com lasi (2017), “[...] o golpe expressou a superação da democracia de cooptação e cedeu espaço para uma nova forma institucional e política" (IASI, 2017, p. 2). Contudo, Demier (2017, p. 100) pondera que, o golpe ${ }^{10}$ de 2016 eleva ao máximo um processo que iniciou com a transição democrática, se intensificou no bojo dos governos da direita neoliberal e atravessou os governos do PT, e encontra seu ápice com a investida golpista que irrompe a consagração de um regime democrático blindado sintonizado com os pressupostos do capitalismo monopolista em tempos de hegemonia das finanças e sob a égide neoliberal.

Cabe salientar que, no processo do golpe presenciamos questionamentos conservadores e reacionários quanto aos (ainda que ínfimos) recursos destinados para a Política de Assistência Social, sobretudo, dos impactos dos programas de transferência de renda aos segmentos subalternizados. Os ataques a tais programas tonificaram as pautas da frente conservadora e reacionária que sustentou o golpe e abriram os caminhos para o avanço das medidas contrarreformistas visando o permanente ajuste fiscal. Em suma, o governo golpista de Michel Temer (2016-2018) ancorado no documento Uma ponte para o futuro ${ }^{11}$, buscou intensificar as investidas contrarreformistas reiterando e reforçando o compromisso estatal com o capital financeiro:

\begin{abstract}
Assumindo a Presidência em 2016, Michel Temer tratou de honrar compromissos com os empresários que bancaram o projeto de sua chegada ao poder. Uma das primeiras medidas adotadas foi a Proposta de Emenda Constitucional (PEC 55/2016) que, após aprovada, é a Emenda Constitucional 95, que congela os gastos públicos, por vinte anos. Apesar de muita resistência, com levantes populares contrários a essa medida, a mesma vem impondo, atualmente, uma série de limites às políticas sociais. A tendência de acentuados e imediatos cortes de gastos é defendida, em diversas partes da proposta do governo (OLIVEIRA, 2019, p. 277).
\end{abstract}

No que tange a Política de Assistência Social, no curso do governo golpista de Michel Temer, concomitante aos ataques das contrarreformas salientadas acima, verificou-se uma

\footnotetext{
10 "Foi um golpe no governo articulado por parte dos aparelhos do Estado como o Parlamento, o Judiciário (com aval da Suprema Corte) e a Polícia Federal; pelos oligopólios da mídia, que atuaram abertamente como os grandes fomentadores e indutores do impeachment; e pela atuação ativa das diferentes frações das classes dominantes e dos setores médios18. Não foi um golpe no regime político, e sim - reiteramos - no governo, o que foi possível pelo próprio funcionamento da institucionalidade democrática restrita, blindada" (DEMIER; DURIGUETTO, 2017, p. 13)

11 “Antes que se concretizasse a Presidência ilegítima de Michel Temer (de 2016 a 2018), o então Partido do Movimento Democrático Brasileiro (PMDB) (hoje MDB), ao qual ele se vincula, apresentou como proposta de plano de governo para o Brasil a programática Uma ponte para o futuro, sob o argumento da necessidade de mudança na direção do Estado brasileiro" (OLIVEIRA, 2019, p. 277).
}

Temporalis, Brasília (DF), ano 20, n. 39, p. 57-69, jan./jun. 2020. | ISSN 2238-1856 
investida direta a essa política com a criação, em Outubro de 2016, do Programa Criança Feliz $^{12}$. Tal programa reforça o apelo ao terceiro setor distanciando do que a LOAS e o SUAS preveem, enquanto prioridade do Estado na oferta de serviços, programas e projetos. Entre tantos equívocos, o programa também serviu para reforçar o primeiro-damismo, a muito combatido por trabalhadoras/es da Política de Assistência Social, com destaque ao Serviço Social, ao ter Marcela Temer como embaixadora.

As contrarreformas de conteúdo notoriamente austericídas, tais como o congelamento dos gastos públicos regulamentados pela EC 95 e o fortalecimento do terceiro setor via investidas como o Programa Criança Feliz, demonstram o fechamento do Estado brasileiro em garantir o que já era residual, em termos de garantia de direitos sociais universais. $\mathrm{O}$ argumento utilizado pelos contrarreformistas ancorou-se mais uma vez na disseminação da cultura da crise (MOTA, 2008), lançando mão de jargões como, por exemplo, a necessidade de tomar o remédio amargo para assim melhorar a economia nacional, aqui as contrarreformas são associadas ao tal remédio amargo, mas o que não foi amplamente divulgado é que apenas um segmento da população é atingido por tais medidas, segmento este historicamente subalternizado por um Estado ausente na implementação de políticas sociais universais.

\section{CONSIDERAÇÕES FINAIS}

As reflexões trazidas neste artigo, demonstraram o campo nebuloso em que a Política de Assistência Social vem sendo organizada e implementada, a partir de uma arquitetura institucional que aponta para o desenvolvimento de um sistema pautado na gestão participativa e descentralizada. Contudo, tal processo está perpetrado pelas contradições históricas próprias da formação econômico e social brasileira que revela ausência histórica do Estado em instituir um sistema de proteção social universal.

Os debates apontam que a tendência que tem direcionando a organização da Política de Assistência Social está atrelada ao ideário neoliberal, não permitindo a ultrapassagem do caráter focalizado, seletivo e consolidando uma cidadania de consumo, configurando um caráter de gerenciamento da pobreza no atual estágio do modo de produção capitalista.

Tais elementos nos convocam a refletir sobre os rumos que a Política de Assistência Social vem tomando, e não só ela, mas o Sistema de Seguridade Social como um todo, uma vez que o mesmo vem sendo mutilado pela agenda contrarreformista neoliberal instaurada no país, o permanente ajuste fiscal, superestimando a macroeconomia em detrimento da garantia de direitos sociais universais e efetivos.

\section{REFERÊNCIAS}

ANTINARELI, et al. Política de assistência social no contexto neoliberal: desafios da

\footnotetext{
${ }^{12}$ Em outubro de 2016, a sociedade brasileira foi surpreendida pelo Decreto $n^{\circ} 8.869$, que instituiu o Programa Criança Feliz - concebido e coordenado pelo Ministério de Desenvolvimento Social e Agrário (MDSA), de responsabilidade de execução da Secretaria Nacional de Assistência Social (SNAS) e nomeando a primeiradama, Marcela Temer, como sua embaixadora - à revelia de qualquer discussão com os Conselhos das políticas da intersetorialidade do Programa (Assistência Social, Saúde, Educação, Cultura, Direitos Humanos, Direitos das Crianças e Adolescentes, entre outros), bem como com os espaços de pactuação (CONSELHO FEDERAL DE SERVIÇO SOCIAL, 2017, p.1)
} 


\section{temporolis}

SILVA, GABRIELE PONCIANO DA

implementação do SUAS. In: DURIGUETO, M.L .; MOLJO, C.B. (Orgs.). Sistema Único de Assistência Social, Organizações da Sociedade Civil e Serviço Social: uma análise da realidade de Juiz de Fora. Juiz de Fora: Ed.UFJF, 2012.

CARCANHOLO, M. D. Inserção externa e vulnerabilidade da Economia brasileira no Governo Lula. In: MAGALHAES, João Paulo de Almeida (Org.). Os anos Lula: contribuições para um balanço Crítico 2003-2010. Rio de Janeiro: Garamond, 2010.

CONSELHO FEDERAL DE SERVIÇO SOCIAL. Nota pública: por que dizer não ao Programa Criança Feliz. Brasília (DF), 2017. Disponível em: http://www.cfess.org.br/arquivos/2017NotaPublicaCFESS-NaoAoProgramaCriancaFeliz.pdf. Acesso em: 27 jan. 2020. DEMIER, F. A. Crônicas do caminho do caos: democracia blindada, golpe e fascismo no Brasil atual. Rio de Janeiro: Mauad X, 2019.

DEMIER, F. A. Depois do golpe: a dialética da democracia blindada no Brasil. Rio de Janeiro: Mauad X, 2017.

DEMIER, F. A.; DURIGUETTO, M.L. Democracia blindada, contrarreformas e lutas de classes no Brasil contemporâneo. Argumentum, Vitória: Revista do Programa de PósGraduação em Política Social da Universdade Federal do Espírito Santo, v.9, n. 2, p. 8-19, maio/ago. 2017.

DURIGUETTO, M.L. Sociedade Civil e democracia: um debate necessário. São Paulo: Cortez, 2007.

IASI, M.L. O PT e a Revolução Burguesa no Brasil. In: IASI, Mauro Luís (Org.). Política, Estado e ideologia na trama conjuntural. São Paulo: Instituto Caio Padro Jr, 2017.

MANDEL, E. O capitalismo tardio. São Paulo: Abril Cultural, 1982.

MONTAÑO, Carlos. Terceiro Setor e Questão Social: crítica ao padrão emergente de intervenção social. São Paulo: Cortez, 2002.

MOTA, A. E. (Org). O Mito da assistência social: ensaios sobre Estado, política e sociedade. São Paulo: Cortez, 2010.

MOTA, A. E. Cultura da crise e seguridade social: um estudo sobre as tendências da previdência e da assistência social brasileira anos 80 e 90. São Paulo: Cortez, 2008.

OLIVEIRA, F. Hegemonia às avessas: decifra-me ou te devoro! In: OLIVEIRA, Francisco et al. (Orgs.). Hegemonia às avessas: economia, política e cultura na era da servidão financeira. São Paulo: Boitempo, 2010.

OLIVEIRA, L. S. Reforma gerencial, neodesenvolvimentismo e ponte para o futuro: recentes contradições das políticas sociais brasileiras. Ser Social, Brasília (DF): Revista do Programa de Pós-Graduação em Política Social, Departamento de Serviço Social da Universidade de Brasília (DF), v. 21, n. 45, p. 263-283, jul./dez. 2019. 
SAAD, A.F; MORAIS, L. Brasil: neoliberalismo versus democracia. São Paulo: Boitempo, 2018.

SCHMID, J. A. C.; SILVA, M. M. A assistência social na contemporaneidade: uma análise no orçamento público. Katálysis, Florianópolis: Revista do Programa de Pós-Graduação em Serviço Social, Curso de Serviço Social da Universidade Federal de Santa Catarina, v. 18, n.1, p. 86-94, jan./jun. 2015.

SIMIONATTO, I. Reforma do Estado e Políticas Públicas: implicações para a sociedade civil e para a profissão. Florianopólis: UFSC, 1999. Disponível em:

http//www.portalsocial.ufsc.br/crise_estado.pdf. Acesso em: 1 jul. 2016.

\section{Gabriele Ponciano da Silva}

Graduada em Serviço Social, pela Universidade Federal do Triângulo Mineiro (2016), doutoranda em Serviço Social pela Universidade Federal de Juiz de Fora. 